\title{
BEHAVIOUR OF SMALL FATIGUE CRACKS IN CU-5.5NI-1.28SI ALLOY ROUND-BAR SPECIMENS
}

\author{
MASAHIRO GOTO ${ }^{1}$, TAKAEI YAMAMOTO ${ }^{1}$, SEUNG ZEON HAN ${ }^{2}$, JEE HYUK AHN ${ }^{2}$, \\ JUNICHI KITAMURA ${ }^{1}$, RYOUTAROU TAKANAMI ${ }^{1}$, TERUTOSHI YAKUSHIJI ${ }^{3}$ \& JEHYUN LEE $^{4}$ \\ ${ }^{1}$ Department of Mechanical Engineering, Oita University, Japan \\ ${ }^{2}$ Korea Institute of Materials Science, Republic of Korea \\ ${ }^{3}$ National Institute of Technology, Oita College, Japan \\ ${ }^{4}$ Changwon National University, Republic of Korea
}

\begin{abstract}
Cu-5.5Ni-1.28Si alloy processed by air-cooling after solution heat treatment was conducted to prevent the generation of discontinuous precipitates which bring a detrimental effect on mechanical properties, and stress-controlled fatigue tests were carried out at room temperature. The change in the surface damage during stressing was monitored by means of both direct observation and plastic replication technique, showing the crack initiation at grain boundaries, crystallographic slip planes and twin boundaries. The growth rate of a small crack can be determined by a term $\sigma_{a}{ }^{n} l$ when $n=5.4$, not by the stress intensity factor range.
\end{abstract}

Keywords: fatigue, copper alloy, crack propagation, microstructure.

\section{INTRODUCTION}

$\mathrm{Cu}-\mathrm{Ni}-\mathrm{Si}$ alloys used for lead frame, connector applications are commercially manufactured through conventional thermomechanical processes, including aging, which induces the continuous precipitation of $\delta-\mathrm{Ni}_{2} \mathrm{Si}$ in the Cu matrix [1]-[3]. Previous studies have focused on $\mathrm{Cu}-\mathrm{Ni}-\mathrm{Si}$ alloys with low solute concentrations (e.g. < 3Ni) [3]-[6] to develop alloys with enhanced tensile properties and electrical conductivity. However, it is well known that an enhancement in the tensile strength of precipitation-hardened $\mathrm{Cu}$ alloys is inevitably accompanied by a reduction in electrical conductivity. For $\mathrm{Cu}-\mathrm{Ni}-\mathrm{Si}$ alloys with high solute concentrations, on the other hand, phase transformation studies have been conducted mainly to control the microstructure of the alloy [7], [8]. In addition, discontinuous precipitates (DPs) that were fibre-shaped, stable $\delta-\mathrm{Ni}_{2} \mathrm{Si}$ intermetallic compounds were formed in the $\mathrm{Cu}$ matrix [9], [10]. The formation of DPs in $\mathrm{Cu}-\mathrm{Ni}-\mathrm{Si}$ alloys is detrimental to their mechanical properties. It was shown that air cooling after solution heat treatment (SHT) encourages formation of disc-shaped $\delta-\mathrm{Ni}_{2} \mathrm{Si}$ precipitates instead of discontinuous precipices [11].

For the envisaged structural applications, a fatigue mechanism, such as crack initiation and propagation, should be clarified. The fracture surfaces of $\mathrm{Cu}-\mathrm{Ni}-\mathrm{Si}$ alloys analysed by a scanning electron microscope (SEM) have showed intergranular facets, leading to a hypothesis that grain boundaries (GBs) were an origin of fatigue crack [12], [13] and fatigue cracks may be propagated along GBs. Up to now, however, there was a small number of clear evidences for crack nucleation and propagation mechanisms [14]. In the evaluation of fatigue life of smooth members, the growth behaviour of a small crack should be clarified, because that the crack growth life from an initial size (grain order size) to $1 \mathrm{~mm}$ accounted for about $70 \%$ of the fatigue life of plain specimens of many metals and alloys. However, the growth rate of small cracks cannot be determined by a linear elastic fracture mechanics [15], [16].

In the present study, fatigue tests of $\mathrm{Cu}-5.5 \mathrm{Ni}-1.28 \mathrm{Si}$ alloy processed by air cooling after SHT were carried out in the room temperature. The objective of this study is to investigate the microstructure produced by air cooling at SHT and the behaviour of initiation and propagation of a surface crack. 


\section{EXPERIMENTAL PROCEDURES}

$\mathrm{Cu}$ and $\mathrm{Si}$ 99.99\% pure and $99.9 \%$ pure Ni were used as alloying elements for the fabrication of the $\mathrm{Cu}-5.5 \mathrm{wt} \% \mathrm{Ni}-1.28 \mathrm{wt} \% \mathrm{Si}$ alloy ingots by induction melting. The ingots were coldrolled with $80 \%$ reduction in thickness, followed by SHT at $980^{\circ} \mathrm{C}$ for $1 \mathrm{~h}$. After the SHT, the samples were cooled by water quenching or air cooling, followed by aging at $500^{\circ} \mathrm{C}$ (Fig. 1). Fig. 2 shows the microstructure with aging times 3 and $6 \mathrm{~h}$ of (a) water quenched and (b) air-cooled alloys. Dark/tarnished phases in water-quenched microstructure after $3 \mathrm{~h}$ aging were DPs. After $6 \mathrm{~h}$ aging, the microstructure was almost completely transformed into DP phases. The formation of DPs in $\mathrm{Cu}-\mathrm{Ni}-\mathrm{Si}$ alloys is detrimental to their mechanical properties. To suppress the formation of DPs, air cooling, instead of water quenching, was applied after SHT. Fig. 2(b) shows the microstructure of air-cooled alloy, showing no generation of DPs even after $6 \mathrm{~h}$ aging. Accordingly, the microstructure, tensile properties and fatigue characteristics were studied on solution treated, air cooled and $6 \mathrm{~h}$ aged $\mathrm{Cu}-5.5 \mathrm{Ni}-$ 1.2Si alloy. The aging duration of $6 \mathrm{~h}$ at $500^{\circ} \mathrm{C}$ yielded near-peak hardness.

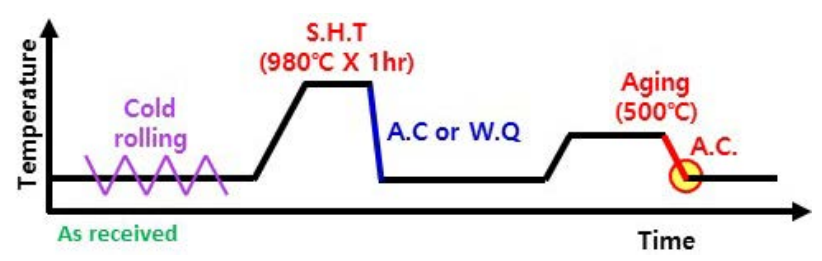

Figure 1: Schematic illustration of thermomechanical process.
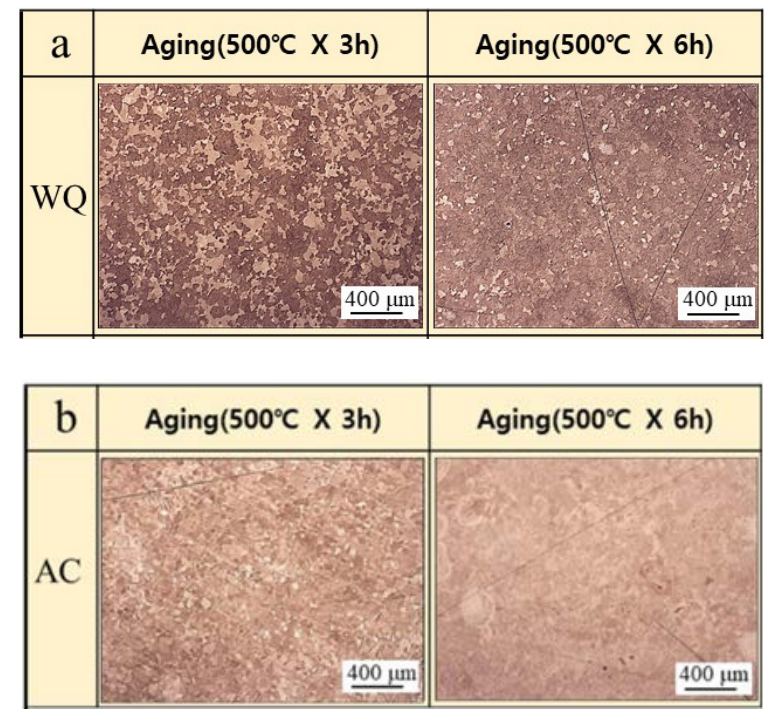

Figure 2: Microstructure after 3 and 6 h aging. (a) Water-quenched; and (b) Air-cooled alloy.

The microstructure was observed using an optical microscope (OM, GX51. Olympus) and a SEM (JSM-6610LV, JEOL). The characterization of precipitates was carried out using a $200 \mathrm{kV}$ field-emission transmission electron microscope (TEM, JEOL-2100F. JEOL) 
equipped with an energy-dispersive X-ray spectroscopy (EDS) detector along with a scanning TEM. The 3-mm-diameter, 100- $\mu$ m-thick disk was prepared for TEM observation by mechanical polishing with a digitally enhanced precision specimen grinder (DEPS-101, Total Solution) and dimpling by a dimple grinder (656 dimple grinder, Gatan).

Tensile tests were conducted on universal testing machine (model: Instron 4206) using $4 \mathrm{~mm}$ diameter round tensile specimens at a strain rate of $0.017 \mathrm{~s}^{-1}$ at room temperature. The microhardness was measured using a Vickers hardness tester with an applied load of $1 \mathrm{~N}$. Round bar fatigue specimens (Fig. 3) with $5 \mathrm{~mm}$ in diameter were machined from the plate of aged alloy. In some specimens, a shallow partial notch (Fig. 3(b); $2.5 \mathrm{~mm}$ radius and $0.1 \mathrm{~mm}$ depth) was machined for monitoring of crack initiation behavior. The fatigue strength reduction factor for the partial notch was close to 1 , meaning that notched specimens could be considered plain. All fatigue specimens were electrolytically polished (approximately $25 \mu \mathrm{m}$ from the surface layer) prior to mechanical testing to remove any preparation-affected surface layer. Polishing was carried out at $25^{\circ} \mathrm{C}$ using an electrolyte consisting of $600 \mathrm{~mL}$ of phosphoric acid, $300 \mathrm{~mL}$ of distilled water, and $100 \mathrm{~mL}$ of sulfuric acid. All fatigue tests were carried out at room temperature using a rotating bending fatigue machine (constant bending-moment type) operating at $50 \mathrm{~Hz}$. The fatigue damage on the specimen surface and on the fracture surface was observed by using OM and SEM. The crack length, $l$, was measured along the circumferential direction of the surface using a plastic replication technique. The stress value referred to is that of the nominal stress amplitude, $\sigma_{a}$, at the minimum cross-section (5 mm diameter).
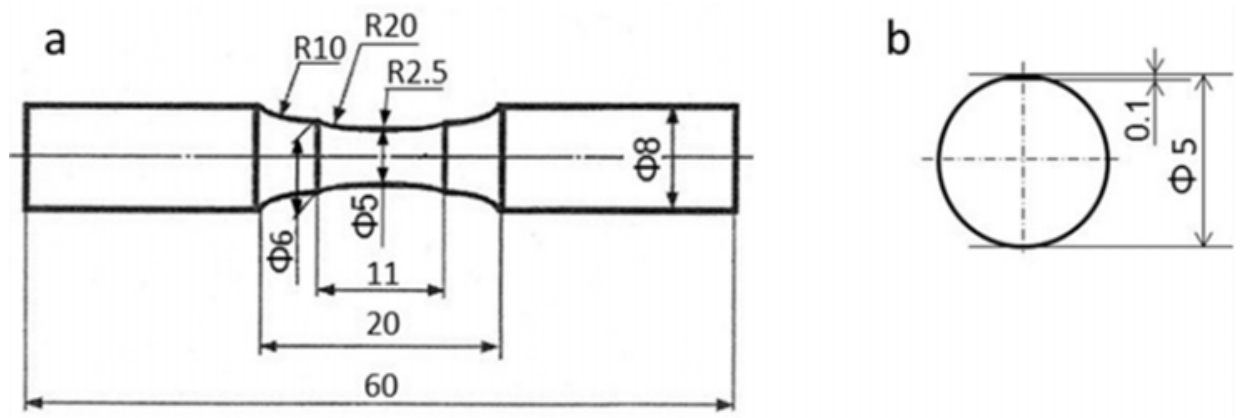

Figure 3: Schematic illustration of fatigue specimen (in $\mathrm{mm}$ ). (a) Shape and dimensions; and (b) The details of a partial notch.

\section{EXPERIMENTAL RESULTS AND DISCUSSION}

Fig. 4(a) shows an optical micrograph of the $\mathrm{Cu}-5.5 \mathrm{Ni}-1.28 \mathrm{Si}$ alloy. Fig. 4(b) and (c) shows TEM images of the matrix. Disc-shaped precipitates were observed, which were identified as $\delta-\mathrm{Ni}_{2} \mathrm{Si}$ intermetallic compounds by an optical diffractogram (Fig. 4(d)). Fig. 5 shows EDS mapping, showing $\mathrm{Ni}_{2} \mathrm{Si}$ precipitations in $\mathrm{Cu}$ matrix.

The stress-strain curves of the air-cooled and water-quenched specimens are shown in Fig. 6. The mechanical properties of the specimens are summarized in Table 1. Indeed, the tensile strength of the water quenched alloy was lower than that of the water cooled one, because of the generation of discontinuous precipitates (Fig. 1(a)). 

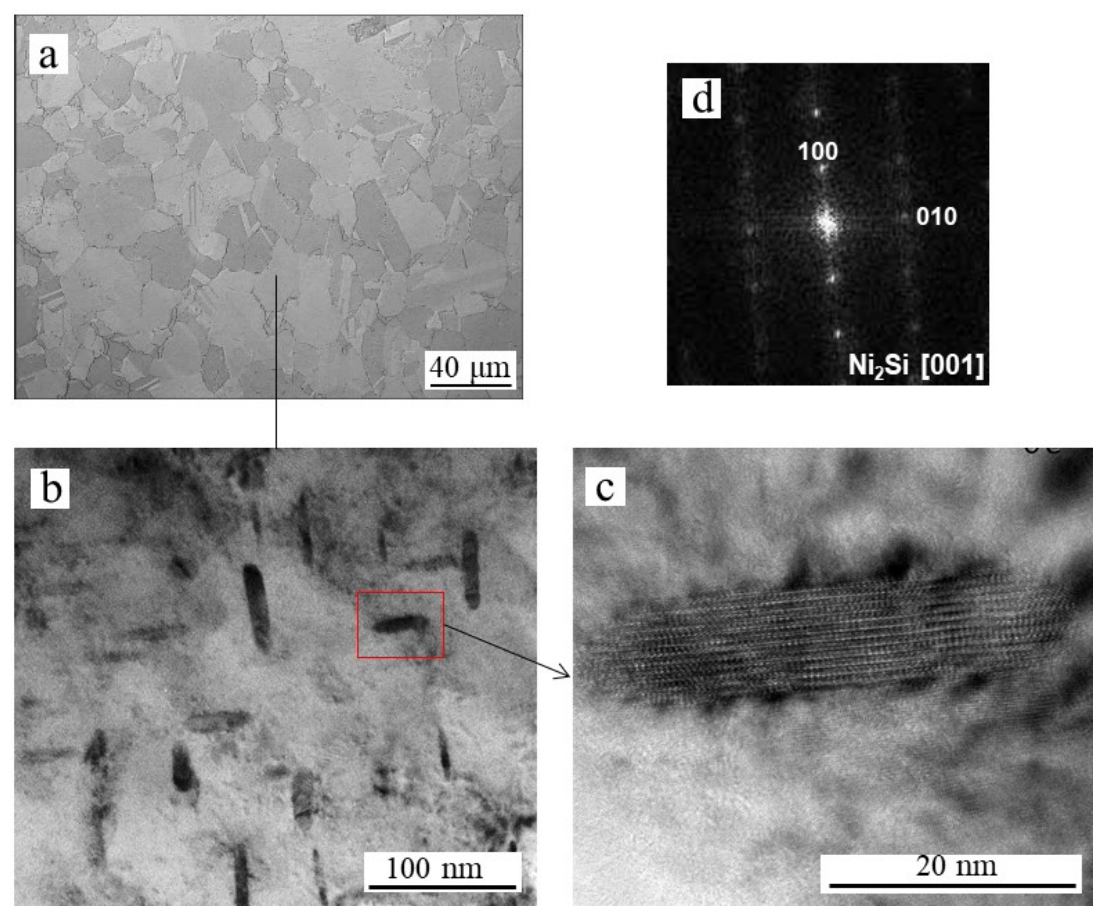

Figure 4: $\quad$ Microstructure of $6 \mathrm{~h}$ aged alloy with air cooling after SHT. (a) OM micrograph; (b), (c) TEM images; and (d) selected area deflection pattern.
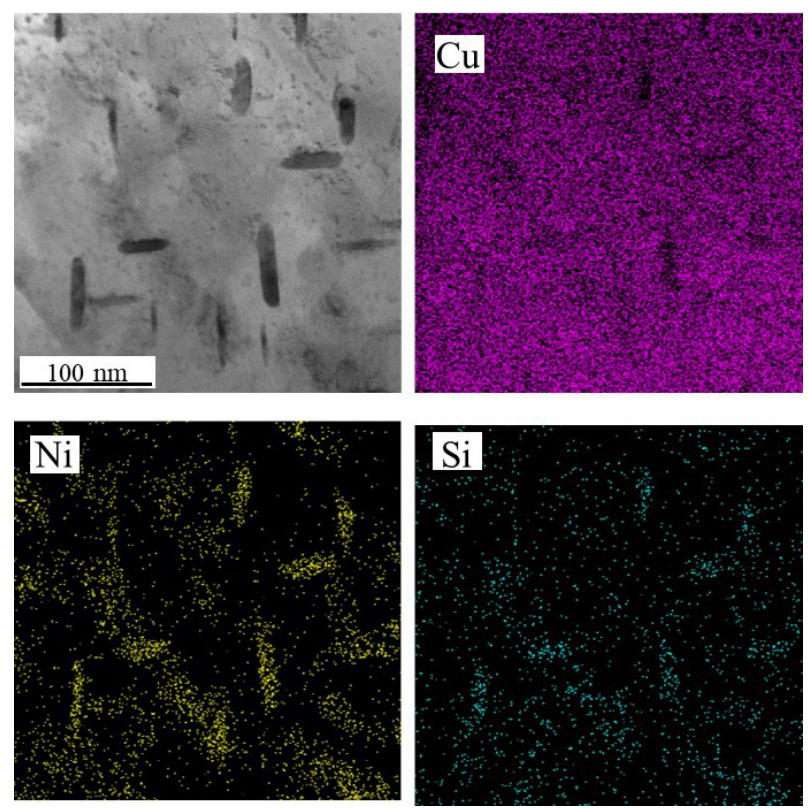

Figure 5: EDS mapping of Cu-5.5Ni-1.28Si alloy. 


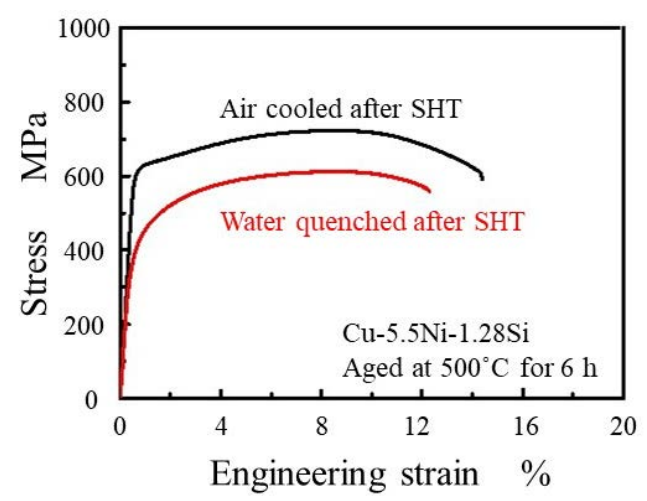

Figure 6: Stress-strain curves of the air-cooled and water-quenched specimens.

Table 1: Mechanical properties of Cu-5.5Ni-1.28Si alloys.

\begin{tabular}{lccc}
\hline Materials & $\begin{array}{c}\sigma_{u} \\
{[\mathrm{MPa}]}\end{array}$ & $\begin{array}{c}\phi \\
{[\%]}\end{array}$ & $H_{V}$ \\
\hline Air cooling & 725 & 14.4 & 233 \\
Water quenching & 616 & 12.3 & 187 \\
\hline$\sigma_{\mathrm{u}}:$ Ultimate tensile strength, & \\
$\Phi:$ Tensile elongation, $H v:$ Vickers hardness
\end{tabular}

The stress vs. number of cycles to failure curves of the air-cooled specimens are shown in Fig. 7. A solid and an open circle shows the S-N plots for without and with notch, respectively. There was no significant difference in S-N plots between without and with notch, meaning the results obtained from the notched specimens can represent that of the plain specimens. A solid triangle shows the S-N plot for an annealed copper ( $99.99 \% \mathrm{Cu})$. Fig. 7 is replotted in Fig. 8 in terms of stress amplitude normalized by tensile strength, $\sigma_{a} / \sigma_{u}$. The ratios of the fatigue limit stress at $N=10^{7}$ cycles, $\sigma_{w}$, to the tensile strength, $\sigma_{u}$, was 0.29 which was lower than that of annealed $\mathrm{Cu}, \sigma_{a} / \sigma_{u}=0.37$.

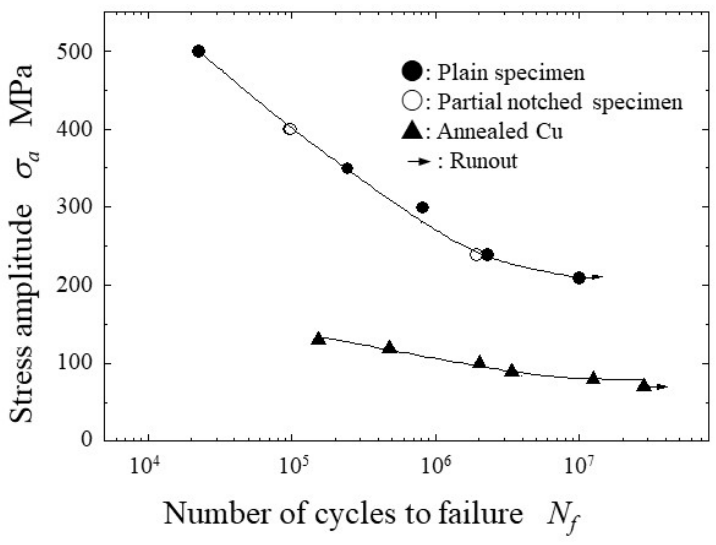

Figure 7: S-N curves of the air-cooled $\mathrm{Cu}-5.5 \mathrm{Ni}-1.28 \mathrm{Si}$ and annealed $\mathrm{Cu}$ specimens. 


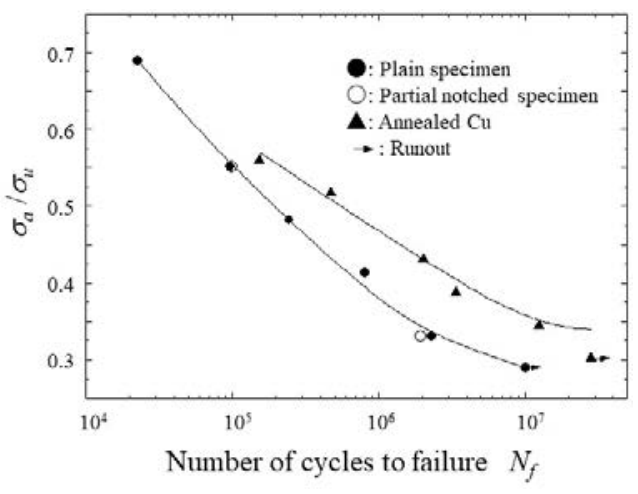

Figure 8: $\quad \sigma_{a} / \sigma_{u}$ vs. $N_{f}$ relationship of the air-cooled Cu-5.5Ni-1.28Si and annealed $\mathrm{Cu}$ specimens.

The changes in the surface morphologies of the air-cooled specimens during cyclic stressing are presented in Fig. 9. To clarify the particular microstructural feature where a crack was initiated, the specimen surface was etched prior to the fatigue test. After the OM analysis of the etched surface, a layer of a few micrometers was polished by buffing to remove the surface area damaged by etching, which would affect the crack initiation behaviour during stressing. The fatigue tests were then conducted. After a fatigue crack was initiated to grain-size length, the fatigue test was interrupted to etch for microstructural observation and then resumed with the etched specimen. Two cracks labelled with I and II were formed at $N=8.5 \times 10^{5}$ on the buffed surface fatigued at $\sigma_{a}=240 \mathrm{MPa}$ (Fig. 9). The length of crack-I at $N=8.5 \times 10^{5}$ was $l=70 \mu \mathrm{m}$. A microstructural comparison between the as-received and as-fatigued specimens suggested that the cracks I and II were initiated at twin boundaries and grain boundaries (GBs), respectively, as indicated by the red arrow in Fig. 9 . In this alloy, cracks were initiated at crystallographic slip planes, GBs, and twin boundaries.

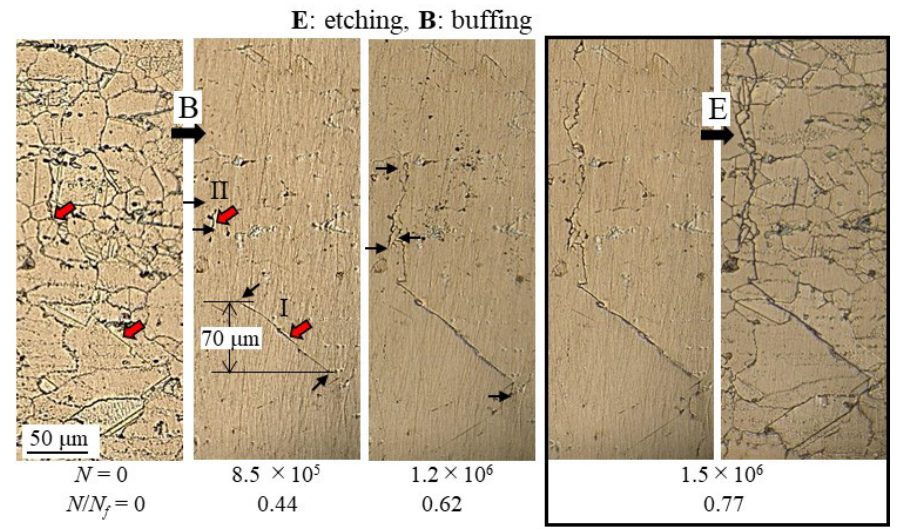

Figure 9: The change in surface states at $\sigma_{a}=240 \mathrm{MPa},\left(N_{f}=1.93 \times 10^{6}\right)$ : To prevent the crack initiation from GBs damaged by etching, etched specimens were fatigued after polishing off a layer of a few micrometres from the surface. After a grainsized crack was initiated, the surface was etched to reveal the microstructure. 
Fig. 10 shows the crack growth curves ( $\ln l$ vs. $N$ ) of the air-cooled specimens. Fig. 10 is replotted in Fig. 11 in terms of number of cycles normalized by fatigue life, $N / N_{f}$. Except for both initial $(l<0.1 \mathrm{~mm})$ and final $(l>2.0 \mathrm{~mm})$ stages of fatigue, the relation can be approximated by a linear relation, whereas the relation for $\sigma_{a}=240 \mathrm{MPa}$ deviated from the linear relation. In the $\ln l$ vs. $N$, the linearity means that the crack growth rate, $d l / d N$, is proportional to the crack length [17], [18].

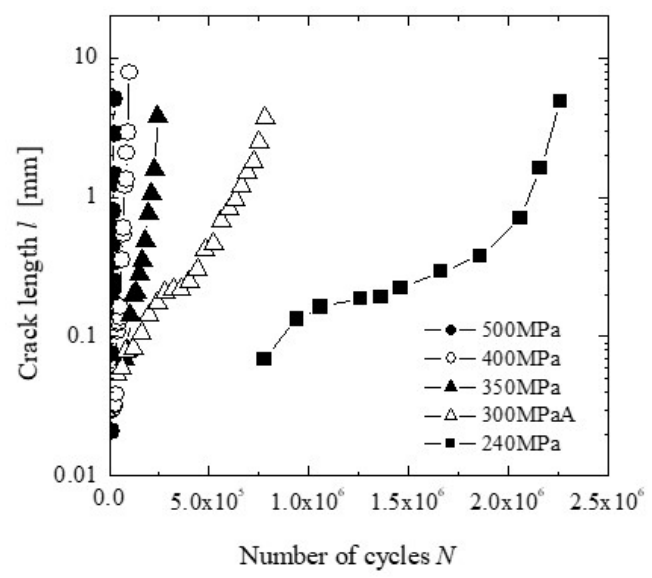

Figure 10: Crack growth curves (lnl vs. $N$ correlation).

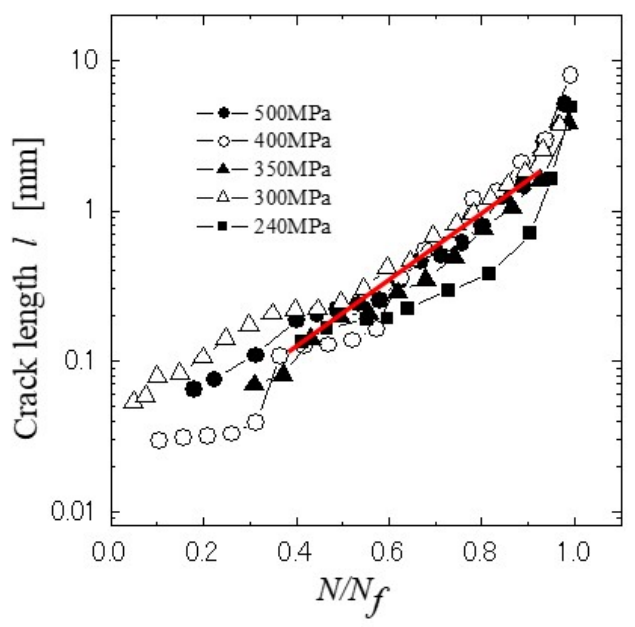

Figure 11: Crack growth curves ( $\ln l$ vs. $N / N_{f}$ correlation).

Fig. 12 shows the crack growth rate as the function crack length: (a) $\sigma_{a}=300 \mathrm{MPa}$ and (b) $\sigma_{a}=350 \mathrm{MPa}$. The crack growth rate in ranging from 0.1 to $2.0 \mathrm{~mm}$ is nearly proportional to the crack length excepting for the threshold region $\left(d l / d N<10^{-6} \mathrm{~mm} / \mathrm{c}\right)$. 

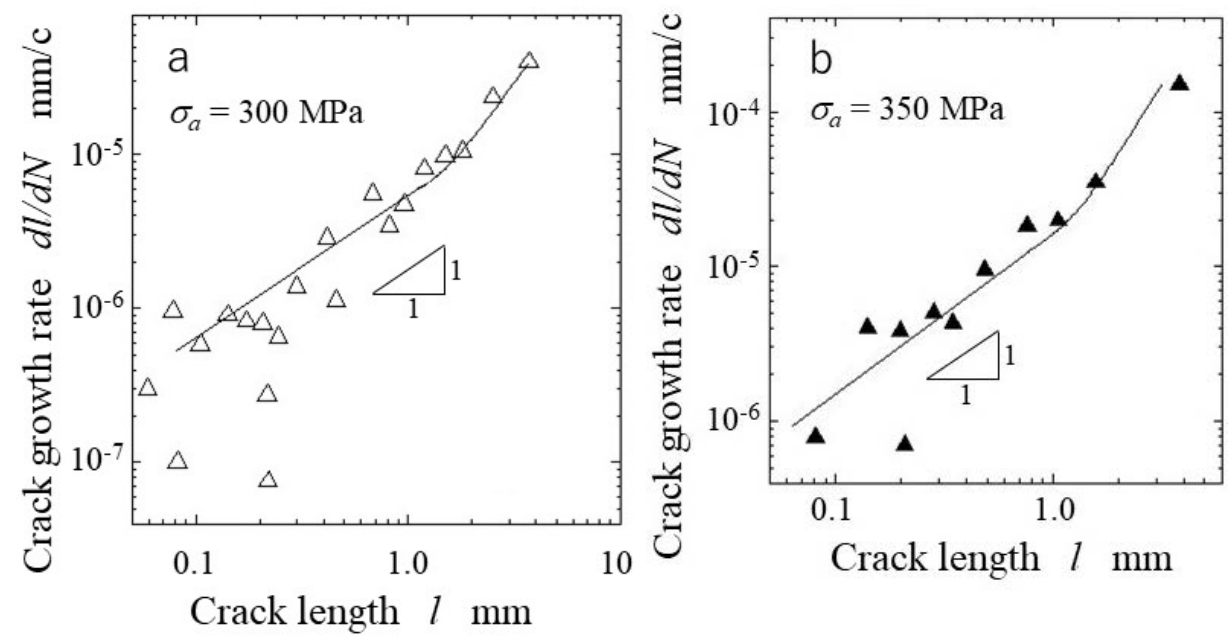

Figure 12: The $d l / d N$ vs. $l$ relationship: (a) $\sigma_{a}=300 \mathrm{MPa}$; and (b) $\sigma_{a}=350 \mathrm{MPa}$.

It has been generally accepted that the growth rate of a large/long crack can be unified in terms of stress intensity factor range (SIFR, $\Delta K$ ) that is an effective parameter for estimation of crack growth rate (CGR) when the condition of small scale yielding at a crack tip is satisfied. However, the growth rate of a small surface-crack, e.g. crack length of less than $1 \mathrm{~mm}$, cannot be evaluated by SIFR [15], [16] unlike a long crack propagating under a low stress amplitude.

Nisitani et al. [17] and Goto and Nisitani [18] proposed eqn (1) for determining the CGR at high stress amplitudes:

$$
\frac{\mathrm{d} l}{\mathrm{~d} N}=C_{1} \sigma_{a}^{n} l,
$$

where $C_{1}$ and $n$ are material constants. The growth data of small cracks in various metals and alloys indicated that $d l / d N$ of a mechanically small crack is uniquely determined by the term $\sigma_{a}{ }^{n} l$ and not by $\Delta K$ [15]-[18]. The expression $\sigma_{a}{ }^{n} l(n=3)$ was first proposed by Frost and Dugdale [19], who applied it to comparatively large cracks in which the condition of smallscale yielding nearly held. Now $\sigma_{a}{ }^{3} l$ can be considered as an approximation for $\Delta K$, whereas the $\sigma_{a}{ }^{n} l$ term proposed by Nisitani and Goto is a parameter for crack propagation under largescale yielding.

Fig. 13 shows the growth data of a small surface-crack with the $d l / d N$ vs. $\sigma_{a}{ }^{n} l$ correlation. The values of $n$ in eqn (1) were 5.4. Excepting a lower stress amplitude ( $\sigma_{a}<300 \mathrm{MPa}$ ), the CGR can be uniquely determined by $\sigma_{a}{ }^{n} l$. Accordingly, the CGR of small cracks propagating at $\sigma_{a} \gtrsim 300 \mathrm{MPa}$ can be approximately estimated by eqn (1). It has been shown that the CGR of small cracks in annealed copper is determined by eqn (1) in the range of $\sigma_{a} \gtrsim 80 \mathrm{MPa}[20]$.

SEM fractographs of the specimen fatigued at $\sigma_{a}=400 \mathrm{MPa}$ and documented at 0.03 and $1.0 \mathrm{~mm}$ beneath the specimen surface are shown in Fig. 14. A notable difference in fracture morphology was observed with depth. The fracture morphology of the subsurface area 


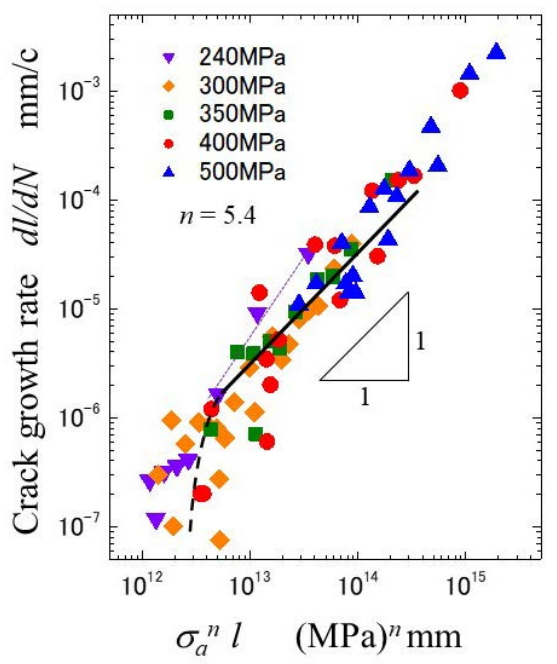

Figure 13: Growth data of small surface-cracks ( $d l / d N$ vs. $\sigma_{a}{ }^{n} l$ correlation: $\left.n=5.4\right)$.

formed by initial crack propagation $\left(d l / d N<10^{-6} \mathrm{~mm} / \mathrm{c}\right)$ appeared to be associated with the remaining microstructural inhomogeneity. For example, uneven surfaces composed of facets were observed; these were probably formed by crack propagation in slip planes within grains and along GBs. In general, a microstructure-sensitive fracture can occur rather easily in the near-threshold and initial stages of crack growth, where the driving force for crack propagation is relatively weak. It has been demonstrated that the propagation of an initial small crack is affected by the presence of microstructural inhomogeneities, such as GBs, phase boundaries, and nonmetallic inclusions [21], [22]. By contrast, the fracture surface far from the specimen surface $\left(\mathrm{dl} / \mathrm{dN}>10^{-6} \mathrm{~mm} / \mathrm{c}\right.$ ) was relatively flat with a smaller occurrence of morphological features associated with microstructural inhomogeneity. Striations (Fig. 14(b)) were frequently observed on the fracture surface, suggesting that crack propagation was largely controlled by mechanical fatigue.
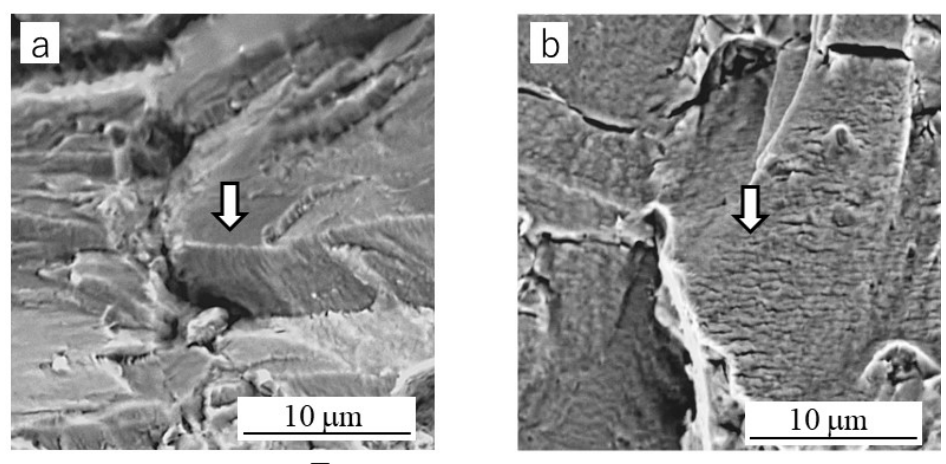

: Crack growth direction

Figure 14: SEM fractographs of the specimen fatigued at $\sigma_{a}=400 \mathrm{MPa}$. (a) $0.03 \mathrm{~mm}$ beneath the surface; and (b) $1.0 \mathrm{~mm}$ beneath the surface. 


\section{CONCLUSIONS}

The main findings of this study on the behavior of fatigue cracks in $\mathrm{Cu}-5.5 \mathrm{Ni}-1.28 \mathrm{Si}$ alloy can be summarized as follows:

1) To prevent the generation of discontinuous precipitates which brings a detrimental effect on mechanical properties and to encourage formation of continuous precipitates, air-cooling was applied after SHT, followed by aging at $500^{\circ} \mathrm{C}$. The matrix was strengthened by disc-shaped $\delta-\mathrm{Ni}_{2} \mathrm{Si}$ intrametric compounds with a few tens of nanometers diameter.

2) The fatigue cracks in the alloy were found to originate from the GBs, crystallographic slip plane and twin boundaries.

3) Except for threshold range ( $d l / d N<10^{-6} \mathrm{~mm} / \mathrm{c}$ ), the growth rate of a small-surface crack propagating at high stress amplitudes ( $\left.\sigma_{a} \succsim 300 \mathrm{MPa}\right)$, can be uniquely determined by a term $\sigma_{a}{ }^{n} l . n$ was material constant and its value was 5.4.

\section{ACKNOWLEDGEMENTS}

This study was supported by a Grant-in-Aid for Scientific Research (Kiban-B) (KAKENHI: No. 18H01340) and for Encouragement of Scientists (No. 18H00244) from the Japan Society for the Promotion of Science, as well as the National Research Foundation of Korea (NRF) grant funded by the Korea government (MSIP) (2018R1A5A6075959). The authors are very grateful to the members of the Strength of Materials Laboratory of Oita University for their excellent experimental assistance. Thanks are also extended to the members of the Korea Institute of Materials Science, for the fabrication of the $\mathrm{Cu}-\mathrm{Ni}-\mathrm{Si}$ system alloys.

\section{REFERENCES}

[1] Corson, M.G., Electrical conductor alloys. Electr. World, 89, pp. 137-139, 1927.

[2] Fujiwara, H., Sato, T. \& Kamio, A., Effect of alloy composition on precipitation behavior in Cu-Ni-Si alloys. J. Jpn. Inst. Metals, 62, pp. 301-309, 1998.

[3] Hu, T., Chen, J.H., Liu, J.Z., Liu, Z.R. \& Wu, C.L., The crystallographic and morphological evolution of the strengthening precipitates in $\mathrm{Cu}-\mathrm{Ni}-\mathrm{Si}$ alloys. Acta Mater., 61, pp. 1210-1219, 2013.

[4] Locker, S.A. \& Noble, F.W., Precipitate microstructure in a Cu-Ni-Si alloy. J. Mater. Sci., 29, pp. 218-226, 1994.

[5] Zhao, D.M., Dong, Q.M., Liu, P., Kang, B.X., Huang, J.L. \& Jin, Z.H., Structure and strength of the age hardened Cu-Ni-Si alloy. Mater. Chem. Phys., 79, pp. 81-86, 2003.

[6] Srivastava, V.C., Schneider, A., Uhlenwinkel, V. \& Bauckhage, K., Effect of thermomechanical treatment on spray formed $\mathrm{Cu}-\mathrm{Ni}-\mathrm{Si}$ alloy. Mater. Sci. Technol., 20, pp. 839-848, 2004.

[7] Lei, Q. et al., Phase transformation behavior in a Cu-8.0Ni-1.8Si alloy. J. Alloys Compds., 509, pp. 3617-3622, 2011.

[8] Shen, L., Li, Z., Zhao, Y., Wang, Y., Dong, Q. \& Wang, M., Phase transformation behavior in a Cu-10Ni-3Al-0.8Si alloy. Mater. Chem. Phys., 173, pp. 421-428, 2016.

[9] Han, S.Z. et al., Increasing toughness by promoting discontinuous precipitation in $\mathrm{Cu}-$ Ni-Si alloys. Philos. Mag. Lett., 96, pp. 196-203, 2016.

[10] Semboshi, S., Sato, S., Iwase, A. \& Takasugi, T.. Discontinuous precipitates in agehardening Cu-Ni-Si alloy. Mater. Characterization, 115, pp. 39-45, 2016.

[11] Han, S.Z., Lee, J., Lim, S.H., Ahn, J.H., Kim, K. \& Kim, S., Optimization of conductivity and strength in Cu-Ni-Si alloys by suppressing discontinuous precipitation. Met. Mater. Inter., 22, pp. 1049-1054, 2016. 
[12] Lockyer, S.A. \& Noble, F.W., Fatigue of precipitate strengthened Cu-Ni-Si alloy. Mater. Sci. Technol., 15, pp. 1147-1153, 1999.

[13] Sun, Z., Laitem, C. \& Vincent, A., Dynamic embrittlement during fatigue of a Cu-NiSi alloy. Mater. Sci. Eng. A, 528, pp. 6334-6337, 2011.

[14] Goto, M. et al., Role of microstructure on initiation and propagation of fatigue cracks in precipitate strengthened Cu-Ni-Si alloy. Inter. J. Fatigue, 87, pp. 15-21, 2016.

[15] Miller, K.J. \& de los Rios, E.R. (eds), The Behaviour of Short Fatigue Cracks, EGFPub 1, MEP, 1986.

[16] Ravichandran, K.S., Ritchie, R.O. \& Murakami, Y. (eds), Small Fatigue Cracks: Mechanics, Mechanisms and Applications, Elsevier, 1999.

[17] Nisitani, H., Goto, M. \& Kawagoishi, N., A small-crack growth law and its related phenomena. Eng. Fract. Mech., 41, pp. 499-513, 1992.

[18] Goto, M. \& Nisitani, H., Fatigue life prediction of heat-treated carbon steels and low alloy steels based on a small-crack growth law. Fatigue Fract. Eng. Mater. Struct., 17, pp. 171-185, 1994.

[19] Frost, N.E. \& Dugdale, D.S., The propagation of fatigue cracks in sheet specimen. $J$. Mech. Phys. Solids, 6, pp. 92-110, 1958.

[20] Goto, M., Kamil, K., Han, S.Z., Euh, K., Kim, S.S. \& Yokoho, Y., Effects of grain refinement due to severe plastic deformation on the growth behavior of small cracks in copper. Inter. J. Fatigue, 50, pp. 63-71, 2013.

[21] Goto, M., Statistical investigation of the behaviour of small-cracks and fatigue life in carbon steels with different ferrite grain sizes. Fatigue Fract. Eng. Mater. Struct., 17, pp. 635-649, 1994.

[22] Goto, M. \& Knowles, D.M., Initiation and propagation behavior of microcracks in Nibased superalloy Udimet 720 LI. Eng. Fract. Mech., 60, pp. 1-18, 1998. 